\title{
Influence of indoor formaldehyde pollution on respiratory system health in the urban area of Shenyang, China
}

\author{
Zhai $\mathrm{L}^{1}$, Zhao $\mathrm{J}^{2}$, Xu B ${ }^{1}$, Deng $\mathrm{Y}^{1}, * \mathrm{Xu} \mathrm{Z}^{1}$ \\ 1. College of Public Health, China Medical University, Shenyang, Liaoning Province, China \\ 2. Department of Pharmacology, Shenyang Pharmaceutical University, Shenyang, Liaoning Province, China
}

\begin{abstract}
Background The decoration of interior spaces can lead to dangerous levels of indoor formaldehyde pollution. Exposure to indoor air pollution may be responsible for nearly 2 million deaths per year in developing countries.

Objectives To assess the prevalence of indoor formaldehyde pollution caused by decoration and resultant respiratory system symptoms exhibited in exposed adults and children, due to indoor formaldehyde pollution caused by decoration. Methods Survey sites were chosen and indoor formaldehyde concentrations determined according to the standard of formaldehyde in GB50325-2001. Logistic regression models were used to derive odds ratios (ORs) and 95\% confidence intervals ( $95 \%$ CIs) after adjusting for potential confounders for this survey.

Results Formaldehyde concentration was above the standard in $64 \%$ of Shenyang City. Some adults surveyed complained of common respiratory system disorders, including coughing (11.8\%), nasal irritation (39.2\%), Heterosmia (14.51\%), and throat irritation (25.27\%); $12 \%$ of children suffered from asthma. The analysis identified formaldehyde pollution and ventilation frequency as risk factors for respiratory system disorders in both adults (OR=2.603, [95\% CI: 1.770-3.828], $\mathrm{OR}=1.604$, [95\% CI: 1.146-2.244], respectively) and children ( $\mathrm{OR}=4.250$, [2.064-8.753], $\mathrm{OR}=1.831$, [1.006-3.333], respectively). Conclusion The prevalence of common respiratory system disorders was related both to formaldehyde pollution and insufficient ventilation after decorating.
\end{abstract}

Key words: Formaldehyde; respiratory system; adult; children

African Health Sciences 2013; 13(1): 137 - 143 http://dx.doi.org/10.4314/ahs.v13i1.19

\section{Introduction}

It is common for homes to be decorated before new occupants move in; however, this may cause indoor air pollution. Among the indoor air pollutants, formaldehyde is most common and its concentration frequently exceeds what is considered to be safe. Formaldehyde can continue to be gradually released from decorating materials and furniture for between 3 and 15 years ${ }^{1}$.

Indoor air pollution is one of the five most harmful environmental factors for human health ${ }^{2}$. A series of health problems have been reported as a result; obesity and hypertension are listed among the top 10 health problems threatening humans. Longterm exposure to polluted air can cause serious health problems; sufferers show varying degrees of symptoms, which include abnormal sense of smell and discomfort, a sense of throat cauterization or

\begin{tabular}{|l|}
\hline *Corresponding author: \\
Zhaofa Xu \\
School of Public Health, China Medical University \\
No.92 Bei'er Street \\
Hepi District, Shenyang 110001 \\
Tel: 00186-24-2325666-5395 \\
E-mail: zfxu@mail.cmu.edu.cn
\end{tabular}

African Health Sciences Vol 13 Issue 1 March 2013 sore throat. And formaldehyde is known to be an irritant to the eye, as well as upper and lower respiratory airways ${ }^{3}$.Even more serious symptoms, such as nausea, vomiting, coughing, asthma, and pulmonary edema, may occur ${ }^{4,5}$. Formaldehyde has been known to be a human carcinogen in the Twelfth Report on Carcinogens, such as Nasopharyngeal Cancer, Sinonasal Cancer, Lymphohematopoietic Cancer, and leukemia ${ }^{6}$. Formaldehyde is omnipresent in indoor environments where children spend most of their time. Children are particularly sensitive to formaldehyde because they are still in the growth and developing stage, including of physical functions. Roda found that infants exposed to formaldehyde at an early age have an increased incidence of Lower respiratory tract infections $(\mathrm{LRI})^{7}$. LRI can be responsible for long term effects on airway function can may cause wheezing ${ }^{8,9}$. The World Health Organization (WHO) declared that worldwide ten million people die annually of asthma induced by indoor air pollution, of which 35 percent are children. But the effect of formaldehyde exposure on children health is unclear.

In this study we aimed to determine the relationship between adult and children's respiratory 
system health and the indoor formaldehyde pollution caused by decoration. This was achieved using a survey of indoor air pollution and its effect on human health. Furthermore, suggestions of how urban residents can avoid respiratory system lesions caused by air pollution will be provided based on the survey results.

\section{Methods}

Experimental methods

From January 10, 2008 to December 30, 2009, 186 residential houses in the main urban area in Shenyang were selected as survey objects. Selection of survey houses was carried out strictly according to the "Code for indoor environmental pollution control of civil building engineering" (GB50325-2001). The houses had been decorated in the previous four years, and occupied within the previous three years.

Formaldehyde was monitored in the bedrooms, living rooms, and kitchens. Before sampling, the doors and windows of the surveyed rooms were closed for at least $12 \mathrm{~h}$. The sampler was situated according to the room area and room type. The sampler was placed further than $0.5 \mathrm{~m}$ from the inner wall, at 0.8-1.5 $\mathrm{m}$ above the floor, in the human breathing zone. Formaldehyde was tested for by the acetylacetone-absorption-spectrometry method according to GB50325-2001. A total of 558 samples were monitored in 186 houses. According to the formaldehyde standard in GB50325-2001 the houses were divided into polluted or non-polluted houses (groups); thus the polluted house (group) contained those that tested positive for formaldehyde concentrations in excess of the hygienic standard $\left(0.08 \mathrm{mg} / \mathrm{m}^{3}\right)$.

The contents and implementation of the questionnaire, and respiratory system health questionnaire, were according to "epidemiological survey questionnaire for the adults and children's health of respiratory systems" designed and recommended by the American Thoracic Society Adult/Children Questionnaire (American Thoracic Society and National Heart and Lung InstituteDivision of Lung Disease Questionnaire of 1978, ATS-DLD-78) ${ }^{10}$ (American Thoracic Society, 1978). One adult was selected randomly from each house to answer the questionnaire, as were 82 children (helped by their parents).

\section{Quality control and statistical analysis}

Before use, all testing equipment was calibrated according to the specifications. For the questionnaire, adults and children were asked to complete the questionnaire face to face.

In the comparison of those with and without a respiratory system disease some variables were dichotomized for ease of interpretation. Smoking in the family was categorized as smoking in the family and no smoking in the family. Formaldehyde concentration in the family was categorized as $<0.08$ $\mathrm{mg} / \mathrm{m}^{3}, 0.08-0.09 \mathrm{mg} / \mathrm{m}^{3}$ and $>0.10 \mathrm{mg} / \mathrm{m}^{3}$. Educational status was dichotomized as with or without college education. Occupation was categorized as work with exposure to air pollution versus all others. Ventilation frequency was dichotomized as $<1$ time/week and $>1$ time/day. Domestic pets was dichotomized as with or without pets in the family. House facing was dichotomized as street or non-street facing. Family history of allergy was dichotomized as with or without having allergy in the family. The multivariate logistic regression analysis forced age (as a continuous variable) and gender into the model and then used forward entry for the other variables (smoking in the family, occupation, education, formaldehyde concentration in the family, ventilation frequency, domestic pets, house facing, family history of allergy, height, weight). Data was double-entered using Epidata 3.1 and analyzed using SPSS 15.0.

\section{Results}

\section{Detection results of formaldehyde}

Of the residential houses tested, 119 were considered polluted and 67 were non-polluted. There were 20 houses containing children in the polluted house (group) and 62 in the non-polluted house (group).Formaldehyde concentration was above the standard in 64\% of Shenyang City houses decorated within the previous four years. The highest value recorded was 14.1 times more than the standard. Formaldehyde concentration in the polluted houses was higher than that of the non-polluted houses in the bedrooms, living rooms and kitchens $(p<0.01$; table 1). Of the 558 rooms sampled, formaldehyde concentrations in 237 rooms were above the standard level: 101 kitchens, 71 living rooms and 65 bedrooms (table 1). Formaldehyde concentration, and the proportion of formaldehyde-polluted rooms, was significantly higher in the kitchens than in the living rooms or bedrooms $(p<0.01)$. Of the 82 houses with children, $24 \%$ contained formaldehyde concentrations above the standard. Formaldehyde concentrations in the polluted houses ranged from 0.01 to $0.55 \mathrm{mg} / \mathrm{m}^{3}$, and the highest 
value was 5.9 times more than the standard value. The formaldehyde concentration in polluted children's bedrooms was significantly higher than that of the non-polluted children's bedrooms $\left(0.123 \pm 0.102\right.$ and $0.043 \pm 0.016 \mathrm{mg} / \mathrm{m}^{3}$, respectively; $p<0.01)$.

Table 1: Formaldehyde concentration of different room types and comparison between polluted and non-polluted homes (mean $\pm \mathrm{SD}$ )

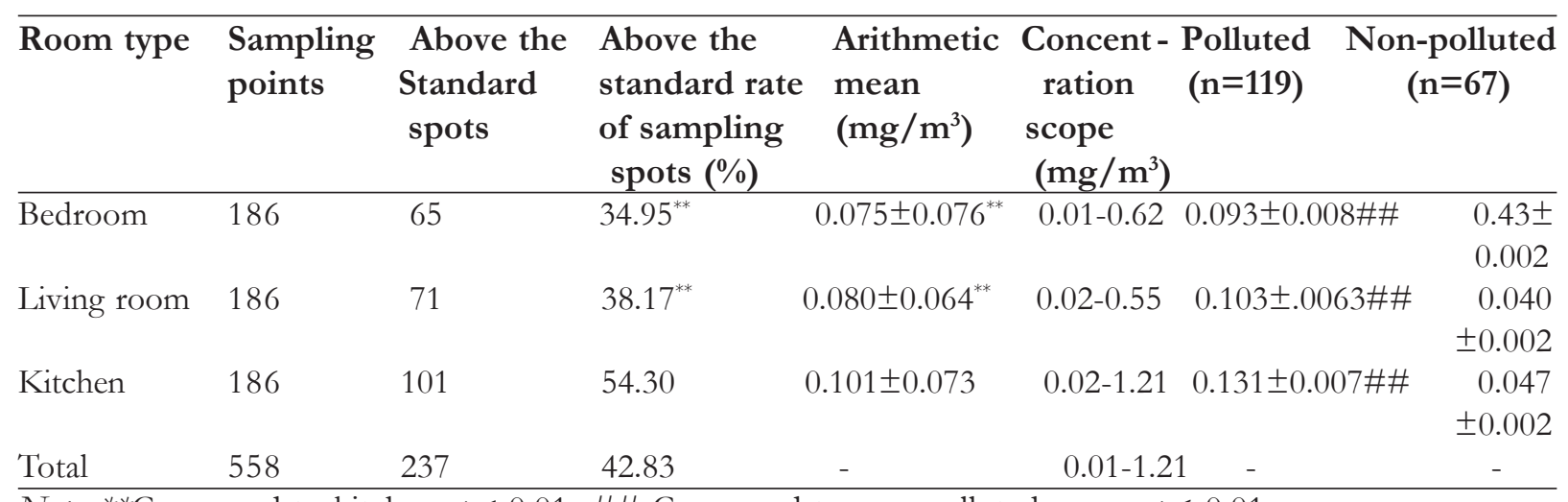

Note. ${ }^{* *}$ Compared to kitchen, $p<0.01$ \#\# Compared to non-polluted group, $p<0.01$

The prevalence of respiratory diseases, symptoms and respiratory health, nervous system and Allergic outcomes

The prevalence of coughing in the polluted adult group was higher than that in the non-polluted group $(p<0.05$; table 2). The prevalence of Asthma in the polluted child group was higher than that in the nonpolluted group $(p<0.05)$. The prevalence of nasal stimulation, throat irritation and Heterosmia was $39.2 \%, 25.27 \%$ and $14.51 \%$, respectively (table 3 ), with higher rates of prevalence in the polluted adult group than in the non-polluted group $(p<0.05)$.

Table 2: The prevalence of respiratory system disorders

\begin{tabular}{llllll}
\hline \multirow{2}{*}{$\begin{array}{l}\text { Symptom of } \\
\text { respiratory } \\
\text { system disease }\end{array}$} & $\begin{array}{l}\text { Polluted } \\
\text { prevalence } \\
\text { rate, \% }\end{array}$ & $\begin{array}{l}\text { Non-polluted } \\
\text { prevalence } \\
\text { rate, \% }\end{array}$ & & $\begin{array}{l}\text { Polluted } \\
\text { prevalence } \\
\text { rate, \% }\end{array}$ & $\begin{array}{l}\text { Non-polluted } \\
\text { prevalence } \\
\text { rate, \% }\end{array}$ \\
\hline Cough & 25.00 & 8.06 & & $15.97 *$ & 4.48 \\
Phlegm & 15.00 & 1.61 & 6.72 & 2.99 \\
Asthma & $40.00^{*}$ & 3.22 & & 1.68 & 0 \\
Wheeze & 10.00 & 6.56 & & 5.04 & 2.99 \\
\hline
\end{tabular}

Note. *Ratio with non-polluted group, $p<0.05$

Independent predictors of respiratory system symptoms in adults and children

Multivariate logistic regression analysis identified independent predictors of respiratory system symptoms in adult and children (table 4). After forcing age (as a continuous variable) and gender into the model, forward entry of the remaining variables identified five independent predictors of respiratory system disorders in adults(table 4), including formaldehyde pollution $(\mathrm{OR}=2.603,95 \%$ CI: $1.770-3.828$, ) and ventilation frequency (OR=1.604, 95\% CI: 1.146-2.244,); neither age nor gender remained significant in the final model. After forcing age (as a continuous variable) and gender into the model, forward entry of the remaining variables identified five independent predictors of respiratory system disorders in children(table 4), including formaldehyde pollution $(\mathrm{OR}=4.250,95 \%$ CI: 2.064-8.753,) and ventilation frequency $(\mathrm{OR}=1.831$, 95\% CI: 1.006-3.333, ); neither age nor gender remained significant in the final model. 
Table 3: The prevalence of respiratory health, nervous system and allergic outcomes in adults

\begin{tabular}{lcccccc}
\hline Respiratory health, Nervous & Total number & Total preval & \multicolumn{2}{c}{ Polluted } & \multicolumn{2}{c}{ Non-polluted } \\
system and allergic outcomes & of people & -ence rate (\%) & n & $\%$ & n & $\%$ \\
\hline Nasal irritation & 73 & 39.2 & 62 & $52.10^{* *}$ & 11 & 16.42 \\
Heterosmia & 27 & 14.51 & 25 & $21.01 * *$ & 2 & 2.99 \\
Oppression, nausea, dizziness & 25 & 13.44 & 19 & 15.97 & 6 & 8.96 \\
Throat irritation & 47 & 25.27 & 38 & $31.93 *$ & 9 & 13.43 \\
Skin hypersensitivity & 6 & 3.23 & 2 & 1.68 & 4 & 5.97 \\
\hline
\end{tabular}

Note: ${ }^{*}$ Compared to non-polluted group $\mathrm{p}<0.05,{ }^{* *}$ Compared to non-polluted group $\mathrm{p}<0.01$

Table 4: Predictors of adults andchildren respiratory system symptoms, as identified by Multivariate Logistic Regression analysis

\begin{tabular}{|c|c|c|c|c|c|c|c|c|}
\hline & Variable & B & S.E. & Wald & d f & Sig & OR & $\begin{array}{l}95 \% \text { C.I. for } \\
\text { OR }\end{array}$ \\
\hline \multirow[t]{4}{*}{ Adults } & $\begin{array}{l}\text { Formaldehyde } \\
\text { concentration }\end{array}$ & 0.957 & 0.197 & 23.644 & 1 & 0.000 & 2.603 & $1.770-3.828$ \\
\hline & $\begin{array}{l}\text { Ventilation } \\
\text { frequency }\end{array}$ & 0.472 & 0.171 & 7.605 & 1 & 0.006 & 1.604 & $1.146-2.244$ \\
\hline & Domestic pets & 0.387 & 0.207 & 3.485 & 1 & 0.062 & 1.472 & $0.981-2.210$ \\
\hline & Constant & -2.792 & 0.154 & 329.260 & 1 & 0.000 & 0.061 & \\
\hline \multirow[t]{4}{*}{ Children } & $\begin{array}{l}\text { Formaldehyde } \\
\text { concentration }\end{array}$ & 1.447 & 0.369 & 15.410 & 1 & 0.000 & 4.250 & $2.064-8.753$ \\
\hline & $\begin{array}{l}\text { Family history } \\
\text { of allergy }\end{array}$ & 0.653 & 0.334 & 3.831 & 1 & 0.050 & 1.922 & 0.999-3.697 \\
\hline & $\begin{array}{l}\text { Ventilation } \\
\text { frequency }\end{array}$ & 0.605 & 0.306 & 3.916 & 1 & 0.048 & 1.831 & $1.006-3.333$ \\
\hline & Constant & -1.567 & 0.441 & 12.642 & 1 & 0.000 & 0.209 & \\
\hline
\end{tabular}

Note. B: partial regression coefficient; S.E.: standard error; Wald: Wald Test; df: degrees of freedom; Sig: P value; OR: odds ratio; C.I.: confidence interval

\section{Indoor decoration and decorating materials}

The comparison of decorative materials and pollution control measures in the polluted and nonpolluted house group are shown in table 5. Univariate analysis showed that formaldehyde pollution could be reduced by using environmentally-friendly decorating materials $\left(28.57 \%\right.$ vs. $71.46 \% ; \mathrm{X}^{2}=32.26$, $p<0.001)$, storing materials for longer after decorating $\left(36.13 \%\right.$ vs. $77.61 \%$; $\left.\mathrm{X}^{2}=29.51, p<0.001\right)$, and increasing ventilation $(25.2 \%$ vs. $43.28 \%$; $\mathrm{X}^{2}=8.269, p=0.016$ ).

\section{Effect of temperature and weather}

We conducted the survey in the spring (March, April, May), summer(June, July, August), autumn(September, October, November) and winter(December, next year January, february), respectively. The number of investigations is 54,47 , 60,25 of spring, summer, autumn and winter, respectively. From figure 1, we found that we survey the indoor temperature in summer was significantly higher than that in the spring, autumn and winter. The concentration of formaldehyde in summer was significantly higher than in spring and autumn. Formaldehyde concentration in winter was also significantly higher than in spring and autumn. 
Table 5: Comparison of decorating materials and pollution control measures in polluted and non-polluted house

\begin{tabular}{|c|c|c|c|c|c|c|c|}
\hline \multirow[t]{2}{*}{ Control measures } & \multicolumn{2}{|c|}{ Polluted } & \multicolumn{2}{|c|}{ Non-polluted } & \multirow[t]{2}{*}{$\boldsymbol{X}^{2}$} & \multirow[t]{2}{*}{$d f$} & \multirow[t]{2}{*}{$\boldsymbol{P}$} \\
\hline & $\mathbf{n}$ & $\%$ & $\mathbf{n}$ & $\%$ & & & \\
\hline \multicolumn{8}{|c|}{ Environmentally-friendly decorative materials } \\
\hline Yes & 34 & 28.57 & 48 & 71.46 & \multirow{2}{*}{32.26} & \multirow[t]{2}{*}{1} & \multirow[t]{2}{*}{$<0.001$} \\
\hline No & 85 & 71.34 & 19 & 28.36 & & & \\
\hline \multicolumn{8}{|l|}{ Storage time after decorating } \\
\hline$>6$ months & 43 & 36.13 & 52 & 77.61 & \multirow[t]{2}{*}{29.51} & \multirow[t]{2}{*}{1} & \multirow[t]{2}{*}{$<0.00$} \\
\hline$<6$ months & 76 & 63.87 & 15 & 22.39 & & & \\
\hline \multicolumn{8}{|l|}{ Ventilation frequency } \\
\hline$<1$ time/week & 61 & 51.26 & 11 & 16.42 & \multirow{4}{*}{8.269} & \multirow[t]{4}{*}{2} & \multirow[t]{3}{*}{0.016} \\
\hline 1 time/week-1 time/ day & 28 & 23.53 & 27 & 40.30 & & & \\
\hline$>1$ time/day & 30 & 25.21 & 29 & 43.28 & & & \\
\hline \multicolumn{6}{|l|}{ Pollution control } & & \\
\hline Yes & 18 & 15.13 & 12 & 17.91 & 0.246 & 1 & 0.62 \\
\hline No & 101 & 84.87 & 55 & 82.09 & & & \\
\hline
\end{tabular}

Note. df: degrees of freedom

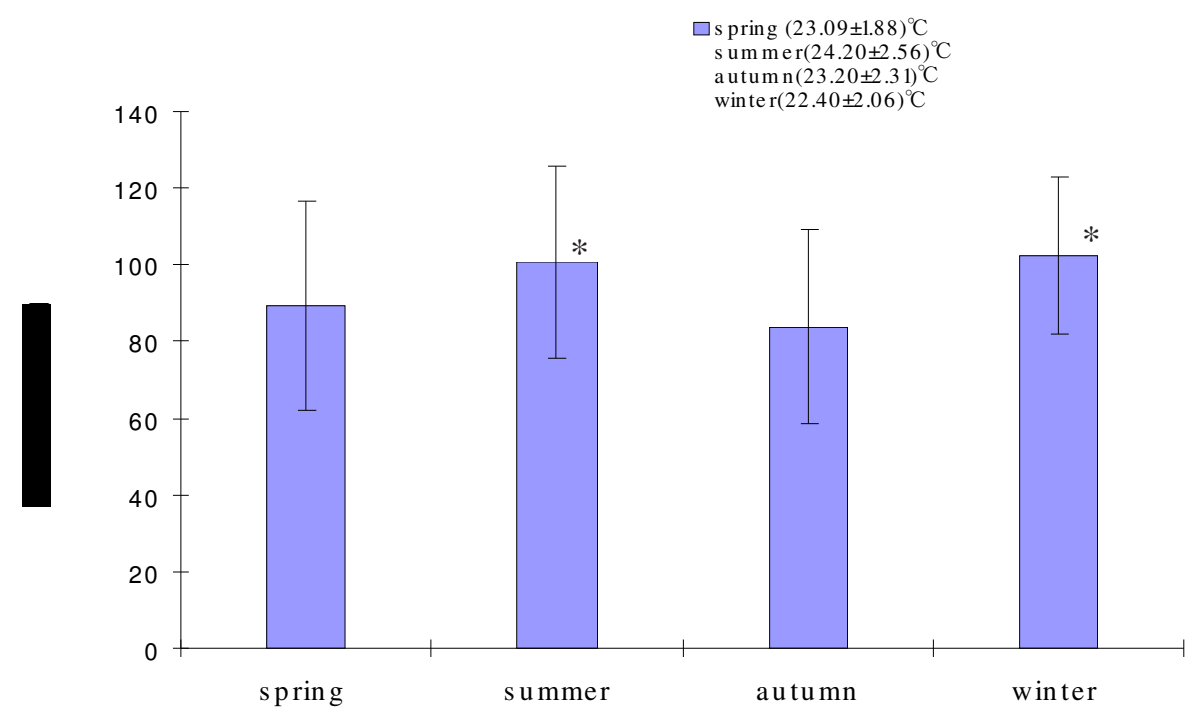

Figure 1: Effect of temperature and weather on indoor formaldehyde in Shenyang, China Homes, $\mathrm{n}=$ number of homes

Note. $*$ Compared to spring and autumn $p<0.05$

\section{Formaldehyde concentration over time}

Considering the combination of data from different houses, formaldehyde concentration increased until it reached a peak value at around the fifth month after decoration, and then gradually decreased (figure 2).

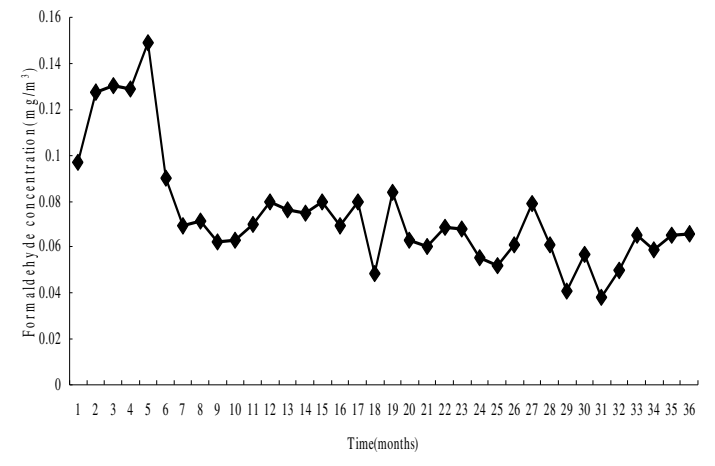

Figure 2: Changes in formaldehyde concentration over time 


\section{Discussion \\ Respiratory system disorders and formaldehyde pollution}

Formaldehyde pollution was monitored in houses that had been occupied for between one month and three years. Liu et al. ${ }^{11}$ investigated the indoor formaldehyde pollution and found the proportion exceeding the standard was $57 \%$. Shang and $\mathrm{Gu}^{12}$ reported that $80 \%$ of 41 family homes investigated in SanMenXia City were polluted, with a highest recorded concentration of $0.82 \mathrm{mg} / \mathrm{m}^{3}$. In Xi'an City, 61\% of 138 newly decorated houses were polluted $^{13}$. Xue et al. ${ }^{14}$ reported that $53.5 \%$ of 83 family homes investigated in ChangSha City were polluted, with the maxium level reached 4.5 times of the standard. Therefore, our findings were similar to other studies.

Similar types of decorating materials were used in both the polluted and non-polluted group. Formaldehyde pollution may therefore be due to the quality of the decorating materials; the families in non-polluted homes tended to use environmentally-friendly decorating materials. Furthermore, the occupants of polluted houses may have failed to take effective measures to eliminate formaldehyde following decoration, or they may have moved into the new house when the formaldehyde concentration was high. Formaldehyde pollution in children's rooms was low, perhaps due to environmentally-friendly decorating materials.

According to our survey, coughing was more common among adults in the polluted group than in the non-polluted group. Du et al. ${ }^{15}$ found that the incidence of releasing of dazzling and pungent gas in newly renovated homes, offices or from new furniture was $59.9 \%$, which led to throat discomfort, foreign body sensation and shortness of breath $(13.3 \%)$, family's cold $(9.2 \%)$, and caused occupants to awake in the early morning feeling dizzy, nauseous and oppressed (7.0\%). It is evident, therefore, that indoor air pollution caused by decorating materials can impact the respiratory system.

Indoor air pollution can harm children in particular, causing the production of mucus and decreasing functioning of macrophages in pulmonary alveoli, which results in chronic cough, bronchial asthma, and repeated respiratory infection. Children may be particularly susceptible to respiratory problems due to indoor air pollution for a few reasons. Firstly, children spend more than $80 \%$ of their time indoors. Secondly, since children are growing, their volume of respiration is $50 \%$ more than adults. Thirdly, there is a relationship between the anatomy of a child's respiratory tract and its immunity characteristics. The respiratory tract can be infected by house dust, microbes, chemical substances, mineral dust, and smoke. Indoor air pollution can induce airway hyper-responsiveness of anaphylaxis in children and inhibit the immune response. This can lead to dyskinesia of the respiratory epithelium cilium and proliferation of respiratory goblet cells. In the survey of children's respiratory system diseases, the incidence of asthma in the polluted group was higher than that of the non-polluted group; thus, a relationship may exist between the respiratory system disease and indoor air pollution.

\section{Effect of temperature and weather}

In high temperature environment, indoor air pollution concentration from harmful substances increase. The temperature has a great impact on the release rate of formaldehyde. And there is a significant positive correlation between the concentration of formaldehyde and temperature. So indoor formaldehyde pollution is very serious in Summer in Shenyang.

It is cold and long of Shenyang (a northern city in china,about3-4 months/year in winter) in winter. The time of heating in winter is about 5 months in Shenyang. Due to the cold, and ventilation frequency decreases, formaldehyde concentration is high in winter in Shenyang. So indoor formaldehyde pollution is very serious in winter in Shenyang.

\section{Protective methods}

There are some ways to reduce the concentration of formaldehyde indoors, such as choosing environmentally-friendly decorating materials, ensuring thorough ventilation, delaying residency, and installing cleansing equipment ${ }^{16-18}$. Our study confirmed that the use of environmentally-friendly decorating materials, longer storage of materials after decoration, and increased ventilation helped to reduce formaldehyde pollution. Our survey also found that formaldehyde concentration decreased six months after decorating. This may be because formaldehyde is a volatile organic compound and, when used in paints, it can be released quickly. Conversely, when formaldehyde is used in manmade planks and sticking material, it may be releases slowly. 


\section{Conclusion}

The prevalence of formaldehyde pollution in Shenyang is similar to other urban cities in China, yet the profile of risk factors is somewhat different. The prevalence of common respiratory system disorders is related both to formaldehyde pollution and little ventilation after decoration. Steps to reduce formaldehyde pollution in urban China must focus on selecting environmentally-friendly decorating materials, increased storage time after decorating and more ventilation time.

\section{Acknowledgements}

We wish to thank all families. Without their cooperation, we could not have completed this project. The authors declare that there is no conflict of interests.

\section{References}

1. Cogliano VJ, Grosse Y, Baan RA, et al. Meeting report: summary of IARC monographs on formaldehyde, 2-butoxyethanoland, 1-tertbutoxy-2-propanol. Environ Health Perspect. 2005; 113(9): 1205-1208.

2. World Health organization. The World Health Report. Geneva, Switzerland, 2002.

3. Wolkoff P and Nielsen GD. Non-cancer effects of formaldehyde and relevance for setting an indoor air guideline. Environ Int. 2010; 36(7): 788799.

4. Ritchie IM and Lehnen RG. Formaldehyderelated health complaints of residents living in mobile and conventional homes. Am J Public Health. 1987; 77(3):323.

5. Collins JJ, Lineker GA. A review and metaanalysis of formaldehyde exposure and leukemia. Regul Toxicol Pharmacol.2004; 40(2): 8191.

6. Report on Carcinogens. Twelfth Edition. U.S. Department of Health and Human Services, 2011.

7. Roda C, Kousignian I, Guihenneuc-Jouyaux C, Dassonville C, Nicolis I, Just J, Momas I. Formaldehyde exposure and lower respiratory infections in infants: findings from the PARIS Cohort Study. Environ Health Perspect. 2011; 119(11): 1653-1658.

8. Gern JE, Busse WW. The role of viral infections in the natural history of asthma. J Allergy Clin Immunol. 2000;106(2): 201-212.
9. Martinez FD, Wright AL, Taussig LM, Holberg CJ, Halonen M, Morgan WJ. Asthma and wheezing in the first six years of life. The Group Health Medical Associates. N Engl J Med. 1995; 332(3): 133-138.

10. American Thoracic Society. Recommended respiratory disease questionnaires for use with adults and children in epidemiological research. Am Rev Respir Dis. 1978; 118: 7-53.

11. Liu H, Han S, Xue Z, et al. Health damage of indoor air pollution by decoration on residents. Journal of hygiene research. 2005; 34(5): 521-523.

12. Shang W, Gu Z. Pollution Survey in 41 newly decorated rooms. Henan Journal Prevention Medicine. 2006; 17(5):282-283.

13. Liu J, Guo Y, Pan X. Study of the current status and factors that influence indoor air pollution in 138 houses in the urban area in Xi'an. Ann N Y Acad Sci. 2008;1140: 246-255.

14. Shengguo X, Yameng M, Lijie L, Yanhong H, Wang J. Investigation of Indoor formaldehyde pollution in newly decorative residences. Journal of Civil, Architectural \& Environmental Engineering. 2011; 33(3):124-128.

15. Du F, Du Q, Xiong X, He L. Invetsigations on awareness and relative health education of indoor air pollution issues among office workers in Chengdu city. Journal of Occupational Health and Damage. 2009; 4(1): 49-52.

16. Johnson T, Myers J, Kelly T, Wisbith A, Ollison W. A pilot study using scripted ventilation conditions to identify key factors affecting indoor pollutant concentration and air exchange rate in a residence. J Expo Anal 2004; 14(1): 122.

17. Fang L, Zhang G, Wisthaler A. Desiccant wheels as gas-phase absorption (GPA) air cleaners: evaluation by PTR-MS and sensory assessment. Indoor Air. 2008;18(5): 375-385.

18. SongJE, Kim YS, Sohn JY. The Impact of Plants on the Reduction of Volatile Organic Compounds in a Small Space. J Physiol Anthropol. 2007; 26(6): 599-603. 